\title{
Social context variables as predictors of smoking cessation
}

Virginia Hill Rice, Thomas Templin, Dorothy H Fox, Patricia Jarosz, Marlene Mullin, Mary Seiggreen, Marybeth Lepczyk

\begin{abstract}
Objective-To examine positive and negative social support and other selected social context variables (age, education, marital status, gender, and exposure to other smokers inside and outside the home) as predictors of smoking cessation in non-hospitalised adults with diagnosed cardiovascular disease at follow up after one, six, and 12 months.
\end{abstract}

Design-Discriminant function analyses (DFA) and longitudinal "lag" analyses.

Subjects-137 Non-hospitalised adults with diagnosed cardiovascular health problems.

Results-Examination of the concurrent DFAs revealed significant univariate $F$ ratios for the predictor variables of gender and marital status at one year and low negative support at all three follow ups. Quitters reported significantly lower levels of negative support than nonquitters over the course of the year and tended to be male and married. Longitudinal "lag" analyses, however, revealed that higher positive social support at one month and higher negative support at six months were both predictive of smoking cessation at one year. At one year more men than women and more married than not married smokers were successful in quitting. No effects for age, education, or exposure to others smoking inside or outside the home were found on any of the concurrent DFAs or longitudinal analyses.

Conclusion-A series of concurrent DFAs revealed that positive support was a significant predictor of quitting at one year and negative support was predictive of not quitting at all three follow ups. Longitudinal "lag" analyses showed that positive support at one month and negative support at six months both predicted quitting at one year. Being male and married were found to contribute to quitting on both sets of analyses. The effects for positive and negative support on the smoking behaviour of adults with cardiovascular disease tended to change over the course of a year. These findings suggest that positive and negative social support may have differential effects over time. As the smoker moves along the "quitting trajectory" it may be that more "nagging" or negative interactions are needed at some point to get smokers to quit, if positive support has not worked or $\vec{\circ}$ is not working. Progression of disease also may have served as a stimulus for family $\vec{\omega}$ members and friends to become more $\vec{D}$ insistent and negative about the person's or continued smoking. More research is needed to examine the quitting process to $\mathscr{O}$ determine which and how social context $ᄋ$ variables contribute.

(Tobacco Control 1996;5:280-285)

Keywords: smoking cessation; social support; cardiovascular disease.

\section{Introduction}

Although cigarette smoking in the US has declined from $40 \%$ in 1965 to $27 \%$ in $1995,{ }^{1}$ it continues to be the number one preventable cause of death and disability from heart disease. $^{2}$ Cigarette smokers have about twice $\stackrel{\square}{\Phi}$ the risk of dying from heart disease as lifetime $\varrho$ non-smokers and cigarette smoking accounts $\overline{0}$ for $30 \%$ of all deaths from heart disease. ${ }^{3}$ Excess risk for cardiovascular health problems can be lowered by about one half after one year of not smoking and, with abstinence, the risk $\overrightarrow{0}$ continues to decline thereafter. ${ }^{4}$ Evidence suggests that the diagnosis and treatment of $\delta$ cardiovascular disease may be an incentive for 0 quitting. ${ }^{5-8}$ In the Coronary Artery Smoking Intervention Study, ${ }^{6}$ patients with the most severe coronary artery disease had the highest 3 quit rates at one-year follow up and $\mathrm{Rice}^{7}$ reported that patients admitted for coronary $₹$ artery bypass graft surgery had higher smoking $ㅇ$ cessation rates than those admitted for medical treatment. Relapse, however, has been found to be a problem with high recidivism rates as early as three months post-intervention. ${ }^{9}$ Factors or found to affect relapse or failure to initiate $N$ quitting in the general population include $\mathrm{N}$ social support, age, education, marital status, 우 gender, and exposure to others smoking inside 0 and outside the home. ${ }^{10-13}$ In this study, these factors were examined relative to smoking cessation over the course of a year in adults with diagnosed cardiovascular disease.

The above factors were viewed as "social context variables" because they helped to define the person's characteristics and position in relation to others in society. ${ }^{14}$ The social o context variable, perceived social support, is a multidimensional concept that refers to the gratification of basic needs relative to affect, affirmation, and aid through interactions with significant others. ${ }^{15}$ Perceived support has been found to exert its influence physiologically (for 
example, reducing the strength of the adrenocorticoid response to stress), psychologically (such as enhancing coping efforts), and behaviourally (for example, facilitating health behaviours such as participation in a cardiac rehabilitation programme). ${ }^{16-20}$ Giannetti et $a l^{21}$ found informal social support, defined as the degree to which people in the subject's social network directly and frequently encouraged cessation, to explain the greatest differences between former and current smokers.

Former smokers-those who had quit at least six months before their hospital admission for cardiovascular health problems-reported receiving significantly higher levels of support in their efforts to quit than current smokers. In prospective studies, naturally occurring support from partners ${ }^{22}$ for individuals trying to quit has been found to be as effective as a programme using spousal training ${ }^{23}$ or partners and support groups in the workplace. $^{94}$ Cohen and Lichtenstein ${ }^{25}$ reported, however, that not all social interactions were supportive of quitting. Their work showed that higher proportions of negative versus positive supportive interactions were consistently better predictors of relapse or continued smoking at follow ups after one, three, six, and 12 months in a sample of essentially healthy adults. Yates et $a l^{26}$ (following an extensive review of the literature) deemed social support to be an important factor in high-risk behavioural change in individuals with diagnosed cardiovascular disease.

Other social context variables found to affect smoking behaviour, directly and indirectly, include age, education, marital status, gender, and the smoking behaviours of others. Studies have shown lower quit rates for older adults, ${ }^{1327}$ for women, ${ }^{1113}$ and for those with less formal education. ${ }^{28}$ Lower quit rates also have been reported for both men and women if divorced, separated, or single compared with those currently married. ${ }^{1012}$ Continued smoking is much more common among adults with higher levels of exposure to other smokers inside and outside the home. ${ }^{1329}$

Our research extended current work on smoking behaviour and smoking cessation in adults with diagnosed cardiovascular problems. The study examined the contribution of a number of social context variables (perceived positive and negative social support, age, education, marital status, gender, daily exposure to others smoking in one's social environment inside and outside the home) over one year. These adults must quit smoking to survive..$^{2-4}$ In addition, this study used prospective lag predictions of quitting based on repeated measures of the social context variables; previous studies have only examined concurrent predictions.

\section{Methods}

SUBJECTS

Of the 255 subjects in a clinical trial study, 137 were selected for this secondary analysis because they had provided complete data on the social context variables of interest. Comparisons of subjects who did and did not provide complete data showed differences $(\mathrm{P}<0.05)$ in perceifved social support, age, education, marital st daily exposure to smoking inside offoutside the home, cigarettes smoked per da years of smoking, interest in quitting, or prior attempts at quitting. Participants were a fonvenience sample drawn from a cityhospitalised, adult population, Фึwho were referred individually to the study by a nurse, physician, other health professiônal, friend, family member, or who referredathemselves. Subjects were eligible for study if they were: 18 years of age or older, smoking 10 more cigarettes per day, and diagnosed with cular health problem. Cardiovasėular conditions included coronary heart disease $(75 \%)$ and peripheral vascular disease $(2 \%)$.

Of the 137 subjects, $42 \%$ were ngen and $58 \%$ were women. Mean age for the sample was 47.6 (SD 12.3) years and mean edication was 12.5 (SD 3.8) years. Sixty one pepcent (61\%) of the sample were married, $90 \%$ Jwere white, and $70 \%$ had occupations with lower middle to upper middle incomes. On average, subjects were smoking 30 (SD 11.5) cigaretees each day and had been smoking for about 28 (SD 11.7) years. Ninety five per cent of the subjects had made at least one previous attemp to quit and the mean number of attempts 3.1 (SD 1.5). In response to a single iten that asked subjects how much they wanted to quit smoking at the time of study intake, thean was 7.8 (SD 1.2) on a nine-point scale; scores ranged from 0 (Not at all) to 9 ( $\forall$ ery much). All subjects had been told by theiriphysician to quit smoking as it was contribufing to their health problem(s) and this nitssage was restated by nurses working on the roject.

MEASURES

Partner Interaction Questionnaire-2ळे(PIQ-20)

Level of social support was deternined by subjects' responses on the PIQ-20. This scale was developed to assess structural and functional support provided specifically by a \$ouse, partner, or significant other during the smoking cessation process and was deriæed from a 61 -item scale. ${ }^{22}$ In our study the shfortened version of the measure (PIQ-20 $0^{25}$ ) was used to assess frequency and perceived helpf hess of support. Computation of scores was fased on the multiplicative approach described by the developers. ${ }^{22}$ Reported internal Consistencies for the PIQ-20 were 0.89 for the 10 -item positive subscale and 0.82 for the 10 -item negative subscale $^{22}$ Internal consistencies the three PIQ-20 reportings in this study 0.87 to 0.91 for the positive subsciale and 0.82 to 0.89 for the negative subscale. P $\mathrm{d}$ Q-20s were completed by subjects at the follow ups after one, six and 12 months.

Demographic Questionnaire $(D Q$

을

On entry into the study, information for the DQ was provided by subjects on their age, education, marital status, and gender. 
Table 1 Univariate $F$ ratios of social context variables

\begin{tabular}{lccc}
\hline & \multicolumn{3}{c}{ Follow up (months) } \\
\cline { 2 - 4 } Social context variables & $1(n=137)$ & $6(n=106)$ & $12(n=95)$ \\
\hline Positive support & 1.35 & 0.15 & $3.82^{\star}$ \\
Negative support & $22.32^{\star \star}$ & $18.96^{\star \star}$ & $4.75^{\star}$ \\
Age & 0.24 & 2.46 & 1.99 \\
Education & 0.22 & 0.07 & 1.95 \\
Exposure inside & 0.35 & 0.01 & 0.13 \\
Exposure outside & 0.52 & 0.10 & 1.92 \\
Marital status & 1.47 & 0.86 & $6.77^{\star}$ \\
Sex & 3.35 & 2.54 & $3.98^{\star}$ \\
\hline
\end{tabular}

$\star P<0.05 ; \star \star ~ P<0.001$.

"Exposure inside" and "exposure outside" refer to the average number of hours of exposure to the smoking of others in the home and at work, respectively.

Table 2. Means and standard deviations (SDs) of social context variables for quitters and non-quitters at the three follow ups

\begin{tabular}{|c|c|c|c|c|c|c|}
\hline \multirow[b]{3}{*}{ Social context variables } & \multicolumn{6}{|c|}{ Follow up (months\} } \\
\hline & \multicolumn{2}{|c|}{$1(n=137)$} & \multicolumn{2}{|c|}{$6(n=106)$} & \multicolumn{2}{|c|}{$12(n=95)$} \\
\hline & Mean & $S D$ & Mean & $S D$ & Mean & $S D$ \\
\hline \multicolumn{7}{|l|}{ Positive support } \\
\hline Quitters & 11.86 & 6.99 & 7.35 & 5.42 & 8.40 & 6.09 \\
\hline Non-quitters & 10.36 & 7.32 & 6.80 & 6.67 & 5.50 & 6.06 \\
\hline \multicolumn{7}{|l|}{ Negative support } \\
\hline Quitters & 3.60 & 4.70 & 3.42 & 4.12 & 4.31 & 4.04 \\
\hline Non-quitters & 8.57 & 65.00 & 9.38 & 6.78 & 7.61 & 6.72 \\
\hline \multicolumn{7}{|l|}{ Age } \\
\hline Quitters & 48.36 & 10.93 & 49.50 & 10.20 & 49.86 & 10.76 \\
\hline Non-quitters & 47.27 & 13.18 & 45.51 & 11.94 & 45.93 & 12.33 \\
\hline \multicolumn{7}{|l|}{ Education } \\
\hline Quitters & 12.75 & 4.16 & 12.67 & 4.27 & 12.63 & 2.01 \\
\hline Non-quitters & 12.43 & 3.58 & 12.44 & 3.55 & 12.68 & 2.99 \\
\hline \multicolumn{7}{|l|}{ Exposure inside } \\
\hline Quitters & 4.91 & 6.08 & 5.26 & 7.25 & 5.51 & 6.89 \\
\hline Non-quitters & 5.61 & 6.92 & 5.19 & 7.45 & 6.16 & 7.23 \\
\hline \multicolumn{7}{|l|}{ Exposure outside } \\
\hline Quitters & 4.68 & 3.51 & 5.07 & 3.99 & 4.18 & 3.81 \\
\hline Non-quitters & 5.18 & 4.13 & 5.35 & 4.16 & 5.61 & 4.37 \\
\hline
\end{tabular}

"Exposure inside" and "exposure ouside" refer to the average number of hours of exposure to the smoking of others in the home and at work, respectively.

Table 3 Results of hierarchical and stepwise discriminant analyses of the social context variables. (Correlations of predictor variables with discriminant function.)

\begin{tabular}{llcc} 
& \multicolumn{3}{c}{ Follow up (months) } \\
\cline { 2 - 4 } Social context variables & $1(n=137)$ & $6(n=106)$ & $12(n=95)$ \\
\hline Stage 1 (forced entry) & & & \\
$\quad$ Positive support & 0.17 & 0.07 & 0.39 \\
Negative support & -0.72 & -0.79 & -0.43 \\
Stage 2 (forward stepwise) & & -0.03 & -0.13 \\
Sex & -0.27 & 0.14 & 0.12 \\
Age & 0.07 & 0.09 & 0.52 \\
Marital status & 0.25 & 0.01 & 0.10 \\
Education & -0.03 & -0.10 & 0.07 \\
Exposure in & -0.16 & -0.01 & -0.09 \\
Exposure out & 0.01 & 0.47 & 0.46 \\
Canonical R & 0.49 & $0.77^{\star}$ & $0.78^{\star}$ \\
Wilks' $\lambda$ & $0.75^{\star}$ & $26.38^{\star}$ & $21.78^{\star}$ \\
$\chi^{2}$ & $36.88^{\star}$ & 77 & 81 \\
Classification (\%) & 76 & &
\end{tabular}

$\star \mathrm{P} \leq 0.001$.
Smoking Behaviour Questionnaire ( $S B Q$ )

Smoking behaviour was assessed using self -1 reports and saliva thiocyanate (SCN) 0 collections. Four questions, which had been $\delta$ used by other researchers, were distributed

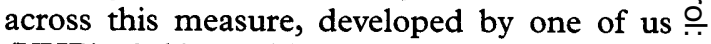
(VHR). Asking subjects to provide essentially $\overrightarrow{\vec{F}}$ the same information in different forms allowed for examination of reporting consistency. A $94 \%$ agreement was found for two of the items in an earlier study. ${ }^{30}$ In this study, degree of agreement among the four differently framed self report items ranged from $75 \%$ to $100 \%$; internal consistency coefficients ranged from $r=0.85$ to $r=1.00$. In addition to self reports, subjects provided saliva samples for thiocyanate testing at each contact and were told that the results would be used to vali- on date their reported smoking behaviour. In our $\vec{i}$ study, the SCN test had low sensitivity and ${ }_{0}$ specificity. Based on the assumption that subjects thought the saliva tests were accurately determining their smoking status, self reports were used as the outcome measure as with the "bogus pipeline" technique. ${ }^{3132}$

\section{PROCEDURE}

On first contact, subjects were given a description of the study, signed an informed consent and completed the DQ and SHQ. At the end of the first session, subjects were told that they would be meeting with the nurse to provide follow-up data in one month, six months, and one year. They were all given a written schedule with the follow-up dates, and a week before data collection subjects were reminded of their appointment by a telephone call from the study secretary. The same nurse met with the same subjects at the same hospital at the follow ups to obtain the PIQ-20 and SBQ and saliva samples for SCN testing.

\section{Results}

Initially, stepwise concurrent discriminant function analyses (DFAs) were used to determine the predictors of cessation at each of the three follow-up points, based on the selected social context variables. Table 1 presents the univariate $F$ ratios for the predictor variables at all three follow ups.

Positive support, marital status, and gender were significant predictors of smoking outcome at one year, and negative support was a factor at all three follow ups. Table 2 presents the descriptive statistics for the social context variables.

At step 1 of each concurrent DFA, positive and negative social support were entered into the equation first, followed by the significant predictor(s) based on Wilks' $\lambda$ analyses. All of the DFAs were significant. Correlations of the predictor variables with the discriminate functions, canonical correlations, $\chi^{2}$ and Wilks' $\lambda$ analyses, and classification percentages are in Table 3.

For the DFA at one month, only negative social support (Wilks' $\lambda=0.85, \mathrm{P}<0.05$ ) was a predictor of smoking behaviour; participants with higher negative support scores reported

\footnotetext{
Smoking Habit Questionnaire (SHQ)

The SHQ asked for a detailed smoking history and included items asking for the average daily number of hours of exposure to the smoking of thers at home and outside the home. Developers $^{30}$ of the SHQ reported a $64 \%$ agreement between subjects' responses and biochemical validation of smoking behaviour on the items for smokers and $100 \%$ agreement for non-smokers.
} 
Table 4 Independent $\mathrm{t}$ test comparisons of social context variables and their $95 \%$ confidence intervals (95\% CI)

\begin{tabular}{|c|c|c|c|c|c|c|}
\hline \multirow[b]{3}{*}{ Social context variables } & & & \multicolumn{2}{|c|}{ Follow up times } & \multicolumn{2}{|r|}{ 음 } \\
\hline & \multicolumn{2}{|c|}{ One month $(n=137)$} & \multicolumn{2}{|c|}{ Six months $(n=106)$} & \multicolumn{2}{|c|}{ One year $(n=95)$} \\
\hline & $\mathrm{t}$ & $(95 \% C I)$ & $\mathrm{t}$ & $(95 \% C I)$ & $\mathrm{t}$ & 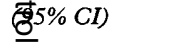 \\
\hline Positive support & -1.17 & $(-4.02$ to 1.03$)$ & -0.39 & $(-3.33$ to 2.34$)$ & $-1.96^{\star}$ & -5.85 to 0.00$)$ \\
\hline Negative support & $4.72^{\star \star}$ & (2.71 to 6.63$)$ & $4.36^{\star \star}$ & (3.24 to 8.66$)$ & $2.18^{\star}$ & जुํ‥29 to 6.30 ) \\
\hline Age & -0.49 & $(-5.44$ to 3.27$)$ & -1.57 & $(-9.02$ to 1.05$)$ & -1.41 & (69.92 to 1.67$)$ \\
\hline Education & -0.48 & $(-1.65$ to 1.01$)$ & -0.27 & $(-1.86$ to 1.41$)$ & -1.40 & (E) 2.30 to 0.40$)$ \\
\hline Exposure inside & 0.60 & $(-1.62$ to 3.03$)$ & -0.05 & $(-2.98$ to 2.84$)$ & 0.37 & 唔 2.80 to 4.10$)$ \\
\hline Exposure outside & 0.72 & $(-0.87$ to 1.88$)$ & -0.32 & $(-1.51$ to 2.09$)$ & 1.39 & $\left(\frac{n}{5} 0.62\right.$ to 3.49$)$ \\
\hline
\end{tabular}

"Exposure inside" and "exposure outside" refer to the average number of hours of exposure to the smoking of otfers in the home and at work, respectively.

significantly lower quit rates. Although men reported receiving more negative support than the women $(t=2.09, \mathrm{P}<0.05,95 \% \mathrm{CI}=4.08$ to 0.11 ), gender as a factor in the DFA did not reach significance $(P=0.06)$. Overall, the variables of positive and negative social support accounted for $25 \%$ of the variance in smoking cessation.

At six months, only negative support (Wilks' $\lambda=0.77, \mathrm{P}<0.001)$ contributed significantly to the DFA. It accounted for $22 \%$ of the variance; non-quitters had significantly higher negative support scores. Although gender was not found to be a factor in quitting at six months, men reported experiencing significantly more positive support then women $(t=$ $2.62, \mathrm{P}<0.05$ (95\% $\mathrm{CI}=3.31$ to 1.72$)$.

For the DFA at one year, three factors were found to contribute to smoking cessation. They were positive support (Wilks' $\lambda=0.96$, $\mathrm{P}=0.05$ ), negative support (Wilks' $\lambda=$ $0.84, P=0.0003$ ), and marital status (Wilks' $\lambda=0.78, P=0.0001$ ) entered after step 1 . Quitters reported having higher levels of both positive and negative support and were more likely to be married than continued smokers. Together, the three variables accounted for $22 \%$ of the variance.

To determine the contribution of social support over and above that of marital status at one year, a fourth DFA was done entering marital status at step 1 followed by social support. This analysis revealed that, after step 1 , positive social support (Wilks' $\lambda=0.88$, $\mathrm{P}<0.03$ ) was a significant predictor of quitting; negative support (Wilks' $\lambda=0.89, P=0.06$ ) was not found to be a significant factor.

Examination of the classification percentages for the three DFAs indicated that three quarters or more of the subjects were correctly designated as smokers or quitters based on the study predictor variables at each of the follow ups (see table 3). Table 4 presents independent $t$ test comparisons of the social context variables with $95 \%$ confidence intervals.

To examine the prospective lag predictions of smoking cessation at one year based on the variables measured at one and six months, longitudinal analyses were conducted. Findings showed that smokers with higher positive social support at one month had higher quit rates at one year $(t=-1.71, \mathrm{P}<0.05,95 \% \mathrm{CI}=14.7$ to 1.17) and smokers reporting higher negative support scores at six months also had higher quit rates at one year $(t=-2.01, \mathrm{P}<0.05$,
$95 \% \mathrm{CI}=19.3$ to 0.05$)$. In additiong $\mathrm{i}, \chi^{2}$ analyses revealed more men (23\%) क्षैan women $(11 \%)\left(\chi^{2}(137)=4.93, P<0.0 \xi\right.$, and more married $(20 \%)$ than unmarried patients $(8 \%)$ $\left(\chi^{2}(137)=4.17, P<0.05\right.$, we\& successful quitters at one year. The variablegof age, education, and exposure to others smoking inside and outside the home did not \&ntribute to either the concurrent DFAs or gongitudinal analyses.

\section{Discussion}

We sought to determine the $\vec{\bullet}$ gelationships among positive and negative socialsupport and other selected social context vapiables (age, education, marital status, gender, 离 exposure to the smoking behaviour of $\overline{\text { Q }}$ thers) with smoking cessation in non-hospitallised adults with diagnosed heart disease over the course of a year. A series of concurrent बliscriminant functional analyses revealed that higher levels of negative support were assegiated with continued smoking at follow up affer one, six, and 12 months. In addition, beingonarried and male contributed to quitting. Age्f, education, and exposure to others smoking inside and outside the home were not found go be predictive factors.

The lack of evidence for positi高 social support as a predictor for quitting is not consistent with findings of Coppotelli and Orleans. ${ }^{10}$ These researchers found "partner facilitation", defined as naturally occurringosupport of smoking cessation by partners, to be the best predictor of smoking cessation follow ups after six to eight weeks in a population of healthy women smokers; it accounted for $32 \%$ of the variance in outcome. Othe significant predictors were: partner quit first woccupation, habitual smoking score, and impertance of a self-mastery objective. Although \$ibjects were asked to identify facilitating $\mathbb{\Phi}_{\infty}$ behaviours performed by their partners, they were not asked to identify partner interactigns that they perceived as non-supportive or negative.

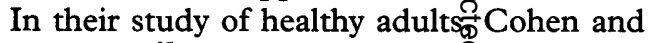
Lichtenstein ${ }^{25}$ found that partners of successful abstainers were perceived as more reinforcing and participated more actively âgd cooperatively in the smoker's quitting ffforts than partners of non-quitters. Nonsjuitters reported experiencing more negative social interactions-for example, partners complaining about their smoking, or partners failing to provide attention to their quitting efforts. 
Findings in our study were similar to those reported by Coppotelli and Orleans ${ }^{10}$ and by Cohen and Lichtenstein ${ }^{25}$ when only the concurrent discriminant analyses are considered. However, longitudinal "lag" predictions revealed that positive support at one month and negative support at six months both predicted quitting at one year.

These findings suggest that positive and negative social support may have differential effects over time-positive social support is effective for some smokers early (one month) in smoking cessation and negative interactions have some immediate negative effects and some long term positive ones. As the smoker moves along the quitting trajectory it may be that more "nagging" or negative interactions are needed at some point to get smokers to quit, if positive support has not worked or is not working. Prochaska and DiClemente ${ }^{33}$ described quitting smoking as a long term process in which smokers move from one stage to another and back and forth as they try to quit. The stages of readiness to change are precontemplation, contemplation, preparation, action, and maintenance. Perhaps the stages of readiness to change and the type(s) of available social support interact in some way.

Another factor, not assessed in this study, which may have contributed to the findings was current health status. As participants in this study were not in hospital, but in the community for each of the follow ups, they may have experienced exacerbation of their heart disease at any point and this could have served as an impetus to quitting. Progression of the disease also may have served as a stimulus for family members and friends to become more insistent and negative about the patient's continued smoking. It is not clear whether continued smoking invited more negative interactions or more negative interactions contributed to continued smoking. Other researchers have reported patients quitting when they learned that they had a cardiovascular health problem and the more severe the heart condition, the greater the likelihood of quitting. ${ }^{568}$ However, we have found no studies that examined the effects of a chronic illness with acute episodes on quitting. More research is needed to examine the quitting process and to determine how factors such as social support and health status affect this process over time.

Other social context variables found in this study to be related to quitting were gender and marital status. Differences were found between men and women: women were less successful in quitting. This finding is consistent with those of other researchers. ${ }^{11-13}$ Factors thought to contribute to this difference include the reasons that women say they smoke. They are more likely to smoke to reduce negative affect and for pleasure. Women are also less confident in their ability to stop, have a greater dependency on cigarettes, and tend to experience less and different social support than men. ${ }^{34}$ Cronenwet $^{34}$ found that men obtained most of their social support from their partners and family members; women received most of their social support from friends.

Further research is needed to clarify the relationships among social support, other social context variables, and quitting smoking to point the way to effective smoking cessation intervention. Most, if not all, men and women have access to a social support network. Thus, it is important to discern how one's social network can best be used to facilitate positive health behaviour changes such as quitting smoking and continued abstinence. Effective interventions are particularly needed for adults who already have evident heart disease as these individuals are at the greatest risk for morbidity and mortality. ${ }^{2-4}$

The study findings can be generalised only to this population of non-hospitalised adults with diagnosed cardiovascular health problems whose reasons for quitting may have been more immediate and more salient than those of a younger, healthy group. The doctors and nurses in this study made the connection between smoking and the subject's health problem very clear when all subjects were advised to quit. It may be in the context of illness that social support has its strongest effect. ${ }^{35}$ Other study findings even suggest that type(s) of social support needed (aid, affective, or affirmation) varies with types of adjustment to illness. ${ }^{36}$ Studies are needed that compare the effects of social support and other selected social content variables in ill and healthy smoking populations and other populations where significant health behavioural changes are warranted. It is also important that other social context variables such as race, culture, and health beliefs be evaluated.

The key to a lifetime of cardiovascular health is to never start smoking. With this in mind, future research also must examine which, if any, of the social context variables, including levels of positive and negative social support, contribute to the initiation of smoking.

Funded by the National Heart, Lung, and Blood Institute and the National Institute of Nursing Research, National Institutes of Health.

1 Escobedo L, Peddicord J. Smoking prevalence in US birth cohorts: The influence of gender and education. $A m \mathcal{F}$ Public Health 1996;86:231-6.

2 US Department of Health and Human Services. The health benefits of smoking cessation. A report of the Surgeon General, 1990. Rockville, Maryland: Public Health Service, Centers for Disease Control, Office on Smoking and Health, 1990 (DHHS Publication No (CDC) 90-8416.)

3 US Department of Health and Human Services. The health consequences of smoking: nicotine addiction. $A$ report of the Surgeon General, 1988. Rockville, Maryland: Public Health Surgeon General, 1988. Rockville, Maryland: Public Health Service, Coffice on Smoking and Health, 1988. (DHHS Publication No (CDC) 88-8406.)

4 US Department of Health and Human Services. Reducing the health consequences of smoking: 25 years of progress. $A$ report of the Surgeon General, 1989. Rockville, Maryland: Public Health Service, Centers for Disease Control, Office on Smoking and Health, 1989. (DHHS Publication No (CDC) 89-8411.)

$5 \mathrm{McSweeney} \mathrm{J.} \mathrm{Making} \mathrm{behavioral} \mathrm{changes} \mathrm{after} \mathrm{a} \mathrm{myocardial}$ infarction. West $\mathcal{F}$ Nurs Res 1993;15:441-5.

6 Ockene J, Kristeller J, Goldberg R, Ockene I, Merriam P, Barrett S. Smoking cessation and severity of disease: The Coronary Artery Smoking Intervention Study. Health Psychol 1992;11:119-26.

7 Rice V, Fox D, Lepczyk MB, et al. A comparison of nursing interventions for smoking cessation in adult with cardio-
vascular health problems. Heart Lung 1994;23:473-86.

8 Orleans CT, Kristeller J, Gritz E. Helping hospitalized smokers quit: New directions for treatment and research. $\mathcal{f}$ Consult Clin Psychol 1993;61:778-89. 
9 Taylor C, Houston-Miller N, Killen J, DeBusk R. Smoking cessation after myocardial infarction: Effects of a nursingmanaged intervention. Ann Int Med 1990;13:118-23.

10 Coppotelli HC, Orleans CT. Partner support and other determinants of smoking cessation maintenance among women. F Consult Clin Psychol 1985;53:455-60.

11 Kabat G, Wynder E. Determinants of quitting smoking. $\mathrm{Am}$ f Public Health 1987;77:1301-5.

12 Orlandi $M$. Gender differences in smoking cessation. Women Health 1987;11:237-51.

13 Lennox A. Determinants of outcome in smoking cessation. Brf Gen Pract 1992;42:247-52.

14 Venters MH, Kottle TE, Solberg L, et al. Dependency, social factors, and the smoking cessation process: The Doctors Helping Smokers Study. Am fo Prev Med 1990;6:185-93.

15 Schaefer C, Coyne J, Lazarus R. The health-related functions of social support. F Behav Med 1981;4:381-406.

16 Sarason B, Pierce G, Sarason I. Social support: The sense of acceptance and the role of relationship. In: Sarason $B$, Sarason I, Pierce G, eds. Social support: an interactional view. New York: Wiley, 1990.

17 Cohen S, Syme S. Social support and health. London: Academic, 1985.

18 Gottlieb B. Marshaling social support: The state of the art in research and practice. In: Gottlieb B, ed. Marshaling social support: formats, processes and effects. Beverly Hills: Sage, 1988.

19 Fleury J. An exploration of the social network in cardiovascular risk reduction. Heart Lung 1993;22:134-44.

20 King K, Reis H, Porter L, Norsen L. Social support and long-term recovery from coronary artery surgery: Effect on patients and spouses. Health Psychol 1993;12:56-63.

21 Giannetti V, Reynolds J, Rihn T. Factors which differentiated smokers from non-smokers among cardiovascular patients: A discriminate analysis. Soc Sci Med 1985; 20:241-5.

22 Mermelstein R, Lichtenstein E, McIntyre K. Partner support and relapse in smoking ces sation programs. $\mathcal{F}$ Consult Clin Psychol 1983;51:465-6.
23 McIntyre-Kingsolver $\mathrm{K}$, Lichtenstein E, Mermelstein R. Spousal training in a multicomponent smoking cessation program. Behav Ther 1986;17:67-74.

24 Glasgow $R$, Klesges $R$, O'Neill $H$. Progranoming social support for worksite smoking modification: extension and replication. Addict Behav 1986;11:453-7.0

25 Cohen S, Lichtenstein E. Partner behavins that support quitting smoking. F Consult Clin Psychol $1890 ; 58: 304-9$.

26 Yates B, Skaggs B, Parker J. Theoretical perspectives on the nature of social support in cardiovascularitiness. 7 Cardiovasc Nurs 1994:9:1-15.

27 Williams E, Winkleby M, Fortmann S. Changes in coronary risk factors in the 1980's: Evidence of a male-female crossover effect with age. Am $\mathcal{F}$ Epidemiol 993 99;137:105667.

28 Burns D. Cigarettes and cigarette smoking $\stackrel{\omega}{\top}$ Clin Chest Med, 1991;12:631-42.

29 Morgan G, Ashenberg A, Fisher E. Abstinence from smoking and the social environment. $f$ Consult Clin Psychol ing and the socia

$1988 ; 97: 238-45$.
Petitti D, Friedman G, Kahn W. Accuracy $\vec{P}$ information on smoking habits provided on self-administered research questionnaires. Am $\mathcal{F}$ Public Health, 1981; $\overline{\text { C }}$ :308-11.

31 Evan R, Hansen W, Mittelmark M. Increasiong the validity of self-reports of smoking be havior in stildren. $\mathcal{F} A p p l$

Psychol 1977;72:521-3.
32 Murray D, O'Connell C, Schmid L, Perry G. The validity of smoking self-reports by ado lescents: A rexamination of the 'bogus pipeline' procedure. Addict Bog 1987;12:7-

king cessation: Implications for clinicians. Clin Chest Med 1991;12;72735.

34 Cronenwett L. Network structure, sociat support, and psychosocial outcomes in preg nancy. Gurrs Res 1985; 34:93-9.

35 Saunders J, McCorkle R. Social support $\frac{\mathbb{D}}{2}$ nd coping with lung cancer. West $\mathcal{f}$ Nurs Res 1987;9:29-4ठ․

36 Primomo J, Yates B, Woods N. Social sup during chronic illness: The relationship among sources and types of adjustment. Res Nurs Health $\$ 990 ; 13: 153-61$.

\section{Helping SMOKers Quit}

The Agency for Health Care Policy and Research (AHCPR) has developed a pocket guide for prima:̊ care clinicians and a quick reference guide for smoking cessation specialists. The guides are designêd to assist in identifying tobacco users, and supporting and delivering effective smoking cessation interventions. For a free copy of either guide, contact AHCPR by mail, phone, fax or on-line.

MAll:

AHCPR Publications Clearinghouse P.0. Box 8547

Silver Spring, MD 20907

PHONE:

$800-358-9295$

\section{FAK:}

AHCPR's InstantFAX, a fax-on-demand service that operates 24 hours a day, 7 days a week. Dial 301-594-2800 from the handset of a fax machine, wait for the automated voice instructions, press 0 and enter 960693 for the Primary Care Clinician Guide or 960694 for the Smoking Cessation Specialist Guide.

ON-LINE:

AHCPR's World Wide Web site: http://www.ahcpr.gov/ 